\title{
DETERMINANTS OF ACCESS AND USE OF IMPROVED WATER SOURCES BY HOUSEHOLDS IN THE NORTHERN REGION OF GHANA
}

\author{
Suuk Janet Lasisa, Nimoh Fred, Tham-Agyekum Enoch Kwame*, \\ Bakang John-Eudes Andivi, Aidoo Robert \\ Department of Agricultural Economics, Agribusiness and Extension, \\ Kwame Nkrumah University of Science and Technology, Ghana \\ *E-mail: ektagyekum@knust.edu.gh
}

\begin{abstract}
This study analyzed the determinants of households' access and use of improved water for domestic purposes in the Northern Region of Ghana, using a survey of 356 households selected using the multi-stage sampling technique. The Logit Regression Model, Multinomial Regression Model and the Kendell's Coefficient of Concordance were the analytical methods employed. The study revealed that the factors that influenced households' choice of water source were level of education, sex of household head, household income, and households' size, especially the number of children in the house and distance to water source. Irregular supply of improved water, an inadequate source of improved water and long queue at water points, in that order of severity were reported as the major constraints to households' access to improved water. The study recommends an income diversification campaign to encourage households to diversify in order to raise their purchasing power for improved water.
\end{abstract}

\section{KEY WORDS}

Access to water, determinants, Ghana, improved water sources, northern region.

Water is an imperative commodity to human lives and it is basic for improvement. Hence, global associations and developed nations continue to focus on it to provide portable water to a large number of the world's populaces who have been denied of water (UN's Earth Summit, 1992). Access to improved water for drinking and other domestic uses is a significant developmental challenge in many developing nations. Over $80 \%$ of the 2.5 billion individuals needing improved water are in Asia and Sub-Saharan Africa (UNICEF/WHO, $2008,2012)$. In a WHO (2010) study, it was reported that only $35 \%$ of the urban populace in Sub-Saharan Africa have access to pipe-borne water in their homes (Zuin et al., 2011). About 663people worldwide depend on unprotected water (e.g. springs, and hand dug wells) and lack improved water sources (UNICEF/WHO, 2015). In Ghana also, generally a greater number of the population which to large extent is greater $40 \%$ of the entire population are deficient in terms of access to water. Records have shown that communities that have no access to portable water have several unwanted consequences for example, poor health and financial burdens. As a result, more income generally is spent on fighting diseases. Research shows that people amounting to 15 million in rural Africa are affected or even give up the ghost every year as a result of water-related diseases (UNICEF/WHO, 2008).

The use of these water sources (unimproved) is often associated with numerous negative results, some of which include; poor health and high burden of disease, economic costs associated with disease, increased mortality, significant burden of time for water collection, social impacts that excessively impact women productivity and children's education, and ultimately a protraction of cyclical poverty. Poor people normally have the least access to proper healthcare (Nwaka, 2005), increased cost of living, lower incomes, riskier lives etc (Bosch et al., 2001).

Montgomery et al., (2009) revealed that the perceptions of users when it comes to water services have links with sustainable water services. Individual perception of good water is influenced by certain cultural and contextual factors. User perceptions, preferences and determinants of these improved water systems are necessary in evaluating likely benefits of these systems including blockades to accessing improved water systems as part 
of the efforts to achieve overall safe water coverage in the country. Literature abounds with many explanations to the differences in access to improved water sources. These include, social factors (household size, gender, age, level of education, marital status), economic factors (household wealth status, employment status), political factors and environmental factors (region of residence, locality (urban/rural) of residence) (Mulengaet al., 2017; Abubakr, 2017; Dil et al., 2015).

In Ghana, only a few studies have investigated the socio-economic structures that increase Ghanaian residents' access to quality water sources (Adams et al., 2016; Boateng et al., 2013). This study, therefore, seeks to illuminate the various factors or determinants of water use in the Northern Region of Ghana.

The main objective of the present study was to determine the factors influencing householders' access to improved water in the Northern Region of Ghana. The specific objectives were:

- To assess the socio-economic characteristics of the household respondents;

- To determine the factors influencing householders' access to different water sources;

- To determine the factors that determine the use of improved water sources;

- To ascertain the constraints to access and use of improved water source by households.

\section{METHODS OF RESEARCH}

Bunkpurugu-Nakpanduriin the Northern Region was used as the study area. The District is located at the North-Eastern corner of the Northern Region of Ghana and shares boundaries in the North with the Garu Tempane, West with East Mamprusi and to the South with Gushiegu and Chereponi Districts and East with the Republic of Togo (GSS, 2014). The area was chosen because with regard to improved water use, it has low patronage. This study employed a cross-sectional research design. Both qualitative and quantitative approaches were employed to provide a better presentation of the data and increase validity by providing the participant with the ability to expand on ideas not offered in the quantitative questions.

A sample size calculation formula propounded by Glaser (1965) to estimate the sample size. At the end, 391 households were selected for the study through the multistage sampling technique. This sampling technique combines a number of sampling techniques with the number of stages depending on the study undertaken (Panneerselvam, 2004). Primary data was gathered from household heads and focus group participants (women and youth groups).

Quantitative data was analyzed using the Statistical Package for Social Scientist version 21, STATA 13, Microsoft Word and Excel. The qualitative data was transcribed, cross-checked and edited. Afterward, they were organized into themes and analyzed. The final output was presented in the forms of texts and direct quotes by respondents under the stated objectives of the study.

Analytical Framework. First of all, qualitative response models otherwise known as chance model that deal with situations with the dependent variable being qualitative in nature such as whether a household uses improved water facilities (Yes) or (No) was used to assess the factors that determine a household's use of improved water source. The response variable here is a binary variable that takes two values, either 1 to represent Yes or 0 as No. The Logit model similar to the probit model was developed to analyse regression framework which have a dichotomous dependent variable. The dichotomous dependent variable takes the form of a dummy, where 1 is yes and 0 is no. Between the two models howevr, economist tend to prefer the Logit over the probit model because it allows for the transformation of a dichotomous dependent variable to a continuous variable hence it gives exact statistical estimates of results. Furthermore, the Logit model has the ability to resolve the problem of heteroscedasticity and also constrain the utility value to lie between 0 and 1 . The method is simple and the results are easily interpreted (Gujarati, 2003). 
Table 1 - Description of the dependent and independent variables used in Logit and multinomial Logit regression models

\begin{tabular}{|c|c|c|c|}
\hline Variable Code & Type of Variable & Description & Expected outcome \\
\hline IMPROV & Dummy & 1 if the main water source is improved, 0 if otherwise & Dependent variable \\
\hline SEX & Dummy & Sex of household head ( 1 if female and 0 if male) & + \\
\hline AGE & Continuous & Age of household head (years) & $-/+$ \\
\hline EDUHEAD & continuous & Number of years in education & + \\
\hline INCOM & Continuous & Household income (in a year) & + \\
\hline NUMCHILDHH & Continuous & Number of children ( $0-9$ years- $\mathrm{WHO}$ ) in a household & - \\
\hline DISTIMPROV & Continuous & Distance to improved water sources $(\mathrm{km})$ & - \\
\hline PERCEP PRICE & Dummy & $\begin{array}{l}\text { Perceived price of improved water (reasonable) } \\
1=\text { Agree, } 0=0 \text { otherwise } \\
1=\text { Neutral, } 0=\text { otherwise } \\
1=\text { Disagree, } 0=\text { otherwise(Base) }\end{array}$ & + \\
\hline PERCEP EASY LATTHER & Dummy & $\begin{array}{l}\text { Perceived softness of improved water } \\
1=\text { Agree, } 0=\text { otherwise } \\
1=\text { Neutral, } 0=\text { otherwise } \\
1=\text { Disagree } 0=\text { otherwise(Base) }\end{array}$ & + \\
\hline PERCEP LOCATION & Dummy & $\begin{array}{l}\text { Perceived location (nearness) of improved water } \\
1=\text { Agree, } 0=\text { otherwise } \\
1=\text { Neutral, } 0=\text { otherwise } \\
1=\text { Disagree, } 0=\text { otherwise(Base) }\end{array}$ & + \\
\hline PERCEP OPENHOURS & Dummy & $\begin{array}{l}\text { Perceived opening hours (favorable) } \\
1=\text { Agree, } 0=\text { otherwise } \\
1=\text { Neutral, } 0=\text { otherwise } \\
1=\text { Disagree, } 0=\text { otherwise(Base) }\end{array}$ & + \\
\hline PERCEP ACCESS TIME & Dummy & $\begin{array}{l}\text { Perceived access time (relatively less) } \\
1=\text { Agree, } 0=\text { otherwise } \\
1=\text { Neutral, } 0=\text { otherwise } \\
1=\text { Disagree, } 0=\text { otherwise(Base) }\end{array}$ & + \\
\hline PERCEP RELIABILITY & Dummy & $\begin{array}{l}\text { Perceived reliability } \\
1=\text { Agree, } 0=\text { otherwise } \\
1=\text { Neutral, } 0=\text { otherwise } \\
1=\text { Disagree, } 0=\text { otherwise(Base) }\end{array}$ & + \\
\hline
\end{tabular}

Source: Field Survey, 2019

The binary Logit model was employed to analyze factors that determine a household's use of improved water sources. The equation for the regression shown below:

Logit regression model is given as: $Y=\beta_{0}+\beta_{1} X_{1}+\beta_{2} X_{2}+\beta_{3} X_{3}+\beta_{4} X_{4}+\ldots \ldots \beta_{n} X_{n}+e$

Where:

$Y=$ dependent variable, $\mathrm{e}=$ error term, $X_{i}=$ independent variables,

$\beta_{i}=$ parameters to be extimated,

$X_{1}=$ sex,$X_{2}=$ age, $X_{3}=$ education, $X_{4}=$ income, $X_{5}=H H$. size (no. of children),

$X_{6}=$ distance, $X_{7}=$ perc price, $X_{8}=$ perc quality, $X_{9}=$ perc openhours, $X_{10}=$ location,

$X_{11}=$ perc access time, $X_{12}=$ perc reliability.

Secondly, to assess the factors that determine a household's use of different water sources, the multinomial Logit model aids in explaining the behaviour of consumers when they are faced with a variety of goods with a common consumption goal. This model was adopted for this analysis as a result of its ability in performing better with discrete choice studies (McFadden, 1974; Judgeet al., 1985). However, the goods must be highly distinguished by their individual attributes. The model examines choice between a set of mutually exclusive and highly differentiated water sources such as borehole, tap, river and well. If only two discrete choices have to be analyzed, the multinomial Logit model reduces to a Logit model (as in the case of improved and unimproved water sources). The probability that a household chooses one source of water is restricted to lie between zero and one. The model assumes that households make water choices that maximize their utility (McFadden, 1974). This study therefore uses multinomial Logit model to estimate the significance of the 
factors believed to influence a household's choice of different water sources in BunkpuruguNakpanduri District. The model can be expressed as follows:

$$
\operatorname{Pr}[Y i=j]=\frac{\exp ((\beta j X i)}{\sum_{j-1}^{J} \exp ((\beta j X i)}
$$

Where:

$\operatorname{Pr}[\mathrm{Yi}=\mathrm{j}]$ is the probability of choosing either borehole, tap, and river with well as the reference water source; $J$ is the number of water in the choice set; $j=0$ is well; $\mathrm{Xi}$ is a vector of the predictor (exogenous) social factors (variables); $\beta j$ is a vector of the estimated.

Thirdly, the Kendall's Coefficient of Concordance (W) was employed to measure the degree of agreement among the constraints to access improved water. This investigation was geared towards finding the total of each constraint ranked while also examining the variability of the totals. The constraint with the minimum score was categorized as the greatest constraint whilst the one with the maximum score is ranked as the lowest constraint.

The score of the ranking was used to compute for the coefficient of concordance (to attain and the degree of agreement). The coefficient of concordance $(W)$ is measured on a scale of between zero (0) to one (1). One when the rank assigned by respondents precisely the same as those assigned by other respondents and zero when there is a maximum level of disagreement among the constraints ranked. The Kendall's coefficient of concordance $(W)$ is given as:

$$
W=\frac{12\left[\sum T^{2}-\frac{\left(\Sigma T^{2}\right)}{n}\right]}{n m^{2}\left(n^{2}-1\right)}
$$

Where: $T=$ the sum of ranks for each factor that is ranked; $m=$ the number of beneficiaries interviewed; $n=$ the total number of rankings.

\section{RESULTS AND DISCUSSION}

This study adopts the definition of head of household given by Ghana Statistical Service (2010), as a member of a household (male or female) who has an economic and social responsibility for the household to define respondents of the study. Based on the frequency analysis in Table 2, majority of the respondents were males, constituting $63.48 \%$ of the sample. Females constituted $36.48 \%$. This may be due to the fact that most household heads in Ghana, Bunkpurugu District not an exception, are headed by males (mostly husbands). The study also revealed that among the respondents, almost half $(47.47 \%)$ had no formal education while $22.47 \%$ reported being educated up to the primary school level.

The results from Table 2 also indicated that more (67.98\%) the household heads were found to be within the married category. Since farming according to Ghana Statistical Service is the dominant occupation in the District, respondents who were farmers dominated $(63.76 \%)$. Farm households were basically into crop (rainfed) and livestock farming, meanwhile it was realized that a high percentage of farm-households' income came from crop farming. However, these households were also found to engage in other income generating activities to complement their income from farming, these activities identified as pito brewing, operation of grinding mails, petty trading etc. become their major income activity during the dry season. Traders followed with $17.13 \%$. Respondents who did not fall within any of the categories of occupation constituted $6.18 \%$, such occupations were termed others and included mechanics and security men. It was also realized from the results that only $5.90 \%$ of heads of households held water management positions. Out of this number (21-5.90\%), $21.05 \%$ were water managers, technicians were $36.84 \%$ and treasurers were $31.58 \%$. The least held portfolio was that of the secretary position.

Average household income from the analysis gave an amount of GHC 6,178 per annum. Spreading average income across the days in a year gives an amount of GHC 17 
per household (of 8 people), placing households in the low income group. As has been established by Omole \& Okunowo (2015) household in such income group has limited opportunities to improve their water situation. Income diversification can serve as a means through which households can increase their income level to provide its members with better lives (improved water consumption).

Table 2 - Socio-demographic characteristics of respondents

\begin{tabular}{|c|c|c|}
\hline Variables & $\mathrm{N}=356$ & Percent (\%) \\
\hline \multicolumn{3}{|l|}{ Sex of Respondents } \\
\hline Male & 226 & 63.48 \\
\hline Female & 130 & 36.52 \\
\hline \multicolumn{3}{|l|}{ Formal Education } \\
\hline No Education & 169 & 47.47 \\
\hline Primary & 80 & 22.47 \\
\hline JHS & 42 & 11.80 \\
\hline SHS/Voc./Technical & 30 & 8.43 \\
\hline Tertiary/Post-Secondary & 35 & 9.83 \\
\hline \multicolumn{3}{|l|}{ Marital Status } \\
\hline Single & 25 & 7.02 \\
\hline Married & 242 & 67.98 \\
\hline Widowed & 66 & 18.54 \\
\hline Divorced & 23 & 6.46 \\
\hline \multicolumn{3}{|l|}{ Main Occupation } \\
\hline Farmer & 227 & 63.76 \\
\hline Teacher & 15 & 4.21 \\
\hline Trader & 61 & 17.13 \\
\hline Driver & 17 & 4.78 \\
\hline Accountant & 3 & 0.84 \\
\hline Nurse & 11 & 3.09 \\
\hline Others & 22 & 6.18 \\
\hline \multicolumn{3}{|c|}{ Hold Water Management Position } \\
\hline Yes & 21 & 5.90 \\
\hline No & 335 & 94.10 \\
\hline \multicolumn{3}{|c|}{ Resp. Water Management Position } \\
\hline Manager & 4 & 21.05 \\
\hline Secretary & 2 & 10.53 \\
\hline Treasurer & 6 & 31.58 \\
\hline Technician & 7 & 36.84 \\
\hline
\end{tabular}

Source: Field Survey, 2019.

Table 3 - Mean statistics of various variables for the multinomial regression

\begin{tabular}{|l|l|l|l|l|}
\hline Variables & Mean of Borehole & Mean of Tap & Mean of River & Total Mean \\
\hline Sex & 0.31 & 0.43 & 0.31 & 0.37 \\
\hline Age & 45.24 & 41.9 & 46.29 & 44.01 \\
\hline Education in years & 4.90 & 7.74 & 1.93 & 4.83 \\
\hline Number of children in HH & 2.18 & 2.42 & 4.31 & 2.90 \\
\hline Household income & 6904.85 & 10156.95 & 8266.44 & 8037.14 \\
\hline Distance_improved & 0.58 & 0.44 & 1.54 & 0.93 \\
\hline
\end{tabular}

Source: Field Survey, 2019.

The mean statistics of the various variables that were used for the multinomial regression show that in terms of age, the highest mean age chose river while the lowest chose tap water. In terms of education, those with the highest level of education chose tap water while those with the lowest chose river. In terms of the number of children in the household, those with the highest number chose river while those with the lowest chose borehole. In terms of household income, those with the highest income chose tap water while those with the lowest income chose borehole. In terms of the distance, the highest distance travelled for water was river while the lowest distance travelled was tap.

The likelihood that aged, highly educated and households with high income prefer tap water could be for reasons of its safety. They are old enough to have had experiences with 
the use of river and borehole and known that the use of tap water is safe. The safety factor could also be the reason educated and high income earners prefer tap water. Tap water in Ghana is a paid commodity and so folks that do not have enough money to cater for their households are unlikely to use it since river is free and borehole is relatively cheaper. What this implies for rural Ghana and Africa is that tap water should be easily accessible and affordable for rural folks. With this in place, water will become a safe commodity for use.

Table 4 - Multinomial regression results of factors that determine a household's use of different water sources

\begin{tabular}{|c|c|c|c|c|c|c|c|}
\hline & Variables & Coefficient & Std Error & $d y / d x$ & Std Error & $z$ & P-values \\
\hline \multirow[t]{6}{*}{ Borehole } & Eduyears & 0.14 & 0.07 & $0.03^{*}$ & 0.02 & 1.92 & 0.06 \\
\hline & $\mathrm{HH}$ Income & 0.00 & 0.00 & 0.00 & 0.00 & 1.58 & 0.12 \\
\hline & Sex & -0.28 & 0.75 & -0.04 & 0.44 & -0.37 & 0.71 \\
\hline & Age & -0.00 & 0.03 & 0.00 & 0.01 & -0.06 & 0.95 \\
\hline & Number of children in $\mathrm{HH} \mathrm{s}$ & -0.48 & 0.18 & $-0.07^{* * *}$ & 0.47 & -2.72 & 0.00 \\
\hline & Distance_improved & -2.87 & 0.54 & $-0.43^{\star \star \star}$ & 2.99 & -5.29 & 0.00 \\
\hline \multirow[t]{6}{*}{ Tap } & Eduyears & -0.08 & 0.13 & -0.00 & 0.05 & -0.59 & 0.55 \\
\hline & $\mathrm{HH}$ Income & 0.00 & 0.00 & $2.14^{\star \star \star}$ & 0.00 & 4.74 & 0.00 \\
\hline & Sex & 1.36 & 1.09 & 0.00 & 1.02 & 1.24 & 0.22 \\
\hline & Age & -0.00 & 0.05 & -0.00 & 0.00 & -0.22 & 0.83 \\
\hline & Number of children in $\mathrm{HH}_{-} \mathrm{s}$ & -1.41 & 0.38 & -0.00 & 0.95 & -3.73 & -3.73 \\
\hline & Distance_improved & -4.21 & 1.09 & $-0.01^{\star \star *}$ & 2.61 & -3.87 & 0.00 \\
\hline \multirow[t]{5}{*}{ River } & Eduyears & -1.35 & 0.35 & $-0.00^{\star \star *}$ & 0.01 & -3.88 & 0.00 \\
\hline & $\mathrm{HH}$ Income & 0.00 & 0.00 & 1.91 & 4.62 & 0.79 & 0.43 \\
\hline & Sex & -0.85 & 0.90 & -0.00 & 0.00 & -0.94 & 0.35 \\
\hline & Age & -0.07 & 0.05 & -1.93 & 0.00 & -1.28 & 0.20 \\
\hline & Number of children in $\mathrm{HH}_{-} \mathrm{s}$ & 0.47 & 0.22 & $0.00^{\star *}$ & 0.00 & 2.15 & 0.03 \\
\hline Well & \multicolumn{7}{|l|}{ Base outcome } \\
\hline
\end{tabular}

Source: Field Survey, 2019.

To find out the factors that influence a household to use a given water source as well as the improved and unimproved source, a multinomial regression and Logit regression were employed respective. Table 4 shows multinomial Logit results of the use of many water sources as borehole, tap, and river as compared to well.

The multinomial regression result shows that the model fits the data well. The pseudo $R 2$ for the Logit estimation is 0.65 . This value of $R 2$ indicates that $65 \%$ of the variation in the water choice is explained by the explanatory variables included in the model. Moreover, the regression provided a log likelihood ratio (LR) statistics which is significant at $1 \%$. This also means that one of the variables has coefficient different from zero showing the appropriateness and the robustness of the Logit model.

With respect to the use of borehole as main water source, three explanatory variables were found to be responsible for the dynamics present. These variables were level of education (10\%), number of children $(5 \%)$ and distance $(5 \%)$. This means that level of education, number of children and distance have a statistically significant influence on the choice of borehole as a major water source. While level of education was positive, number of children and distance were negative. The implication is that an increase in the level of education of the household head influences their use of borehole as a water source and vice versa (Engel et al.,2005). Meanwhile, a decrease in the number of children in the household and the distance rather influences their choice of borehole as the major water source. Education must become an integral element among the rural folks for them to appreciate the use of borehole water because the more educated they are, the more they will tend to use borehole. The size of a household is a key in the use of borehole. This is due to the fact that more of them are needed to fetch water from a borehole. The distance to a borehole if (Rauf et al., 2015). This probably answers the negative co-efficient.

With respect to the use of tap as main water source, two explanatory variables were found to be responsible for the dynamics present. These variables were household income 
(5\%) and distance (5\%). This means that household income and distance have a statistically significant influence on the choice of tap as a major water source. While household income was positive, distance to the water source was negative. The implication is that an increase in the household income will influence their use of borehole as a water source and vice versa. Since tap water is not free in Ghana, it sounds to reason that those with high income will prefer it to other sources of water (high income are more likely to use improved. This result is in variance with that of (Engel et al., 2005). Meanwhile, a decrease in the distance will rather influence their choice of borehole as the major water source. This will mean that tap water must be made easily accessible by reducing the distance from the source to the household. There should be a possibility for every household or a couple of households to own their own tap so that its use can be increased (Boone et al., 2011).

With respect to the use of river as main water source, two explanatory variables were found to be responsible for the dynamics present. These variables were educational level $(5 \%)$ and number of children (5\%). This means that educational level and number of children have a statistically significant influence on the choice of river as a major water source. While level of education was negative, number of children in the household was positive. The implication is that a decrease in the level of education of the household head will influence their use of borehole as a water source and vice versa. Meanwhile, an increase in the number of children in the household will rather influence their choice of borehole as the major water source. Same as borehole, education must become an integral element among the rural folks for them to appreciate the use of river. However, in this case, those with lower educational levels are the ones going to use river. However, education is still necessary in attempting to draw them from its usage except in cases where it is not going to affect their health. The size of a household is also a key in the use of river, same as the case of borehole. This is due to the fact that more of them are needed to fetch water from a river. It is actually an exciting adventure when a good number of children decide to walk together to access water from a riverside (Rauf et al., 2015).

Table 5 - Logit regression results of factors that determine a household's use of improved water sources (using odds ratio)

\begin{tabular}{|c|c|c|c|c|c|c|}
\hline Variables & Coefficient & Std Error & Odds Ratio & Std Error & $z$ & $\mathrm{P}$-values \\
\hline Eduyears & $0.10^{*}$ & 0.06 & 1.11 & 0.07 & 1.68 & 0.09 \\
\hline $\mathrm{HH}$ Income & $0.00^{* \star *}$ & 0.00 & 1.00 & 0.00 & 3.45 & 0.00 \\
\hline Sex & $0.84^{*}$ & 0.51 & 2.33 & 1.19 & 1.66 & 0.09 \\
\hline Age & -0.03 & 0.02 & 0.97 & 0.02 & -1.46 & 0.15 \\
\hline Number of children in $\mathrm{HH}$ & $-0.71^{\star \star \star}$ & 0.14 & 0.49 & 0.07 & -4.89 & 0.00 \\
\hline Distance_improved & $-3.17^{\star * *}$ & 0.48 & 0.04 & 0.02 & -6.62 & 0.00 \\
\hline \multicolumn{7}{|l|}{ Percep_location } \\
\hline Neutral & 0.78 & 0.64 & 2.19 & 1.39 & 1.23 & 0.22 \\
\hline Agree & 0.22 & 0.68 & 1.25 & 0.85 & 0.32 & 0.75 \\
\hline \multicolumn{7}{|l|}{ Percep_price } \\
\hline Neutral & 0.01 & 0.66 & 1.01 & 0.66 & 0.02 & 0.99 \\
\hline Agree & -0.47 & 0.71 & 0.62 & 0.44 & -0.67 & 0.50 \\
\hline \multicolumn{7}{|l|}{ Percep_open $\sim \mathrm{hrs}$} \\
\hline Neutral & $-2.03^{\star * \star}$ & 0.61 & 0.13 & 0.08 & -3.34 & 0.00 \\
\hline Agree & 0.49 & 0.59 & 1.63 & 0.96 & 0.83 & 0.41 \\
\hline \multicolumn{7}{|l|}{ Percep_access_time } \\
\hline Neutral & 1.17 & 0.73 & 3.22 & 2.34 & 1.61 & 0.11 \\
\hline Agree & 0.86 & 0.58 & 2.36 & 1.36 & 1.49 & 0.14 \\
\hline \multicolumn{7}{|l|}{ Percep_Reliability } \\
\hline Neutral & $-2.46^{\star \star *}$ & 0.95 & 0.09 & 0.08 & -2.59 & 0.01 \\
\hline Agree & -0.49 & 0.49 & 0.61 & 0.29 & -1.01 & 0.31 \\
\hline \multicolumn{7}{|l|}{ Percep_Easy_lather } \\
\hline Neutral & $1.21^{*}$ & 0.70 & 3.35 & 2.35 & 1.72 & 0.09 \\
\hline Agree & $-1.83^{*}$ & 0.49 & 0.16 & 0.08 & -3.71 & 0.09 \\
\hline cons & 4.51 & 1.59 & 90.70 & 144.78 & 2.82 & 0.01 \\
\hline
\end{tabular}

Source: Field Survey, 2019. 
It was also imperative to unearth the factors influencing the use of water from improved sources so that paying key attention to factors found significant during provision water systems will step up the use of such improve water interventions. Hence a Logit regression was run. The results of the summary of mean by categories of improved and unimproved users are presented in Table 5.

The results of the Logit regression indicate that the data fits well in the model with a pseudo $R 2$ estimation of 0.53 . This value of $R 2$ shows that $52.69 \%$ of the variation in the water choice is explained by the descriptive variables included in the model. Also the log likelihood ratio (LR) of the regression signifies a $1 \%$ significant level. This also means that one of the variables has coefficient different from zero showing the appropriateness and the robustness of the Logit model. Choice of a particular water source is significantly determined by education status of household head, household income, sex of household head, number of children in a household, distance to improved water sources and some household perception on improved water as shown in Table 5. All the significant variables are in conformity with the apriori expectation.

Education attainment of household head was significant at $10 \%$ and had a positive effect on improved water use. It indicates that the higher the level of education of a household head, the greater the probability of a household to use improved water compared to the less educated household heads. Education surely has an influence on the choice of improved water use. Boone et al., (2011) and Engel et al., (2005) also found that the number of years spent in school has an influence on the choice of a water source. They associated this phenomenon with increased use of public taps and reduced use of wells. It is also significant in communities where a per-bucket charge applies. The implication is that rural communities need to be educated in their choice of improved water source. This is due to the fact that it will greatly influence its usage; else, they may tend to use other source of water that may be injurious to their health.

Household income also shows a positive coefficient and a statistically significant relationship with the use of improved water. Use of improved water increases with household's income and thus increasing household income is likely to increase their use of improved water. Households with high income are more likely to use improved water sources. This study confirms the studies of Boone et al., (2011) and Rauf et al., (2015). In their studies, they found that the use of improved water increases when a household asset (income) is high. This implies, that though improved water services should be charged, it should be targeted more at users within high-income bracket if users within the low-income group are to be able to access and use such services. This result is in variance with that of Engel et al., (2005) who found a negative relationship between income and use of improved water in areas where charges apply.

Sex of household head indicates a positive coefficient and is significant at a level of $10 \%$ with improved water use. This suggests that household heads who are females are more likely to use improved water as compared to their male counterparts. Engel et al., (2005) agrees with this result and asserts that household heads who are women are more likely to use the improved source in areas where flat rate charges as compared to men. This can be explained from the viewpoint that, water is used more often by women for domestic chores like cooking, washing, etc. by women, labeling them as main water users and managers of the home and because of this close interaction become more likely to go for improved which in her opinion is safe for their families. On the other hand, females tend to be affected more in the course water disease outbreak, hence their efforts to ensure the health of their household.

Size of children comprising the household size has a negative sign and statistically significant at $1 \%$ level of significance. The result shows that if the number of children increases, the probability of households to use improved water will reduce. This finding is similar to that of Rauf et al., (2015) who found that family size is an important determinant as it was significantly related to the choice of a water source. A study by Engel et al., (2005) also revealed that the larger a household, the less likely they will be in use of improved 
source especially in communities charging per bucket and more likely to use it when a flat rate or no charge is applied.

The model estimation results indicate that distance to an improved water source was significant at $1 \%$ in the study area and exerted a negative effect on the use of improved water in the area. This means that an extension in the distance to an improved water source by at least $1 \mathrm{~km}$ is likely to decrease the probability of a household using that improved source compared to using unimproved sources. This reveals that the further the improved water from household the less likely they are to use it. This finding corresponds to the results of previous studies. A study by Boone et al., (2011) indicated that distance to available water sources play an important role in the choice of a water source, they, therefore, concluded that a decrease in the distance to one type of water source presents the household more likely to switch from other sources to the use that source. Given this sensitivity to distance, they suggested that infrastructure investments that provide more (and closer) sources of drinking water will lead to changes in household behavior. Meanwhile, Rauf et al., (2015) also found the distance between water source and house to be highly significant with a negative sign.

The regression model also revealed that respondent's perception is significant to improved water use. Studies like Doria et al., (2009), Wright et al., (2012) and Rojas and Megerle (2013) indicate that perceptions of physical attributes as taste, color and odor as well as their perception of health risk go a long way to shape user behavior, choices, and preferences to different water sources. However, the study found a negative relationship in most cases, where positive perception did not lead to an increase in the use of improved water use as expected but its use rather declined. Previously, even though respondents were seen to have positive perception regarding open hours for improved water which signifies easy accessibility, reliability of improved water, and its (improved) ability to lather easily with soap, the relation turned out negative showing a reduction in use. These unexpected findings could be attributed to the fact that the use of these improved sources attracts a fee, coupled with issues of inadequacy, unreliability as identified earlier by respondents. This led to a reduction its (improved water) use even though households perceive them to be of higher quality and relatively safe for use.

Table 6 - Descriptive statistics of constraints to access improved water

\begin{tabular}{|c|c|c|c|c|}
\hline Constraints to access improved water & $\mathrm{N}$ & Mean & Std. Deviation & Rank \\
\hline Inadequate source of improved water & 356 & 4.39 & 2.82 & $2^{\text {nd }}$ \\
\hline Irregular supply & 356 & 3.11 & 2.31 & $1^{\text {st }}$ \\
\hline Long distance & 356 & 5.73 & 2.71 & $9^{\text {th }}$ \\
\hline Cost of improved water & 356 & 5.07 & 2.37 & $4^{\text {th }}$ \\
\hline Long queue at water points & 356 & 4.79 & 2.27 & $3^{\text {rd }}$ \\
\hline Belief system held by a household & 356 & 5.66 & 2.17 & $8^{\text {th }}$ \\
\hline Poor management of water & 356 & 5.44 & 1.82 & $6^{\text {th }}$ \\
\hline Discrimination at water point & 356 & 5.38 & 2.44 & $5^{\text {th }}$ \\
\hline Break out of quarrels & 356 & 5.59 & 3.17 & $7^{\text {th }}$ \\
\hline \multicolumn{5}{|l|}{ Test Statistic } \\
\hline Number of observations & \multicolumn{4}{|l|}{356} \\
\hline Kendall's W'a & \multicolumn{4}{|c|}{0.09} \\
\hline Chi-Square & \multicolumn{4}{|c|}{261.03} \\
\hline Degree of freedom (Df) & \multicolumn{4}{|l|}{8} \\
\hline Asymptotic significance & \multicolumn{4}{|c|}{0.00} \\
\hline
\end{tabular}

Sources: Field Survey, 2019. NB: The results from the Kendall's coefficient (W) ranges from $0-1$. The case of 0 means perfect disagreement (they do not agree with any of the identified constraints) among the rankers while the case of 1 is a perfect agreement which connotes that all the ranks match for every constraint identified.

Table 6 outlays the descriptive statistics on the constraints to access improved water by 356 respondents. The Kendell ' $W$ ' was used to measure the level of agreement among the rankers (household heads). From the results, the most important constraints for household to access improved water was the irregular supply of water (3.11) and the least important constraint was long distance (5.75). Other three high constraints that limit households' access to improved water were inadequate source of improved water (4.39), 
long queue at water points (4.79) and cost of improved water (5.05). From a study by Adebisi et al., (2017) on the constraints of rural households to access improved water in Oyo State, they reported that inadequate source of improved drinking water was the key constraints and resulted to use of river water, streams by households. Further discussion revealed that the limited number of boreholes and public standpipes experience regular break-downs probably because of so much pressure on them, this break-down they lamented takes longer periods to be repaired leaving them with no better option than falling back on wells and rivers.

These constraints cause communities to get into water stress periods, where women and children have to trek for about 6 kilometers each day to collect water (Ladele and Tackie-Ofosu, 2013). The long queues and daily conflicts they endure at water collection points are only but a few of the frustrations they go through when water systems are broken down. The burden of water scarcity on women is greatly increased when they have to household members who get ill from take unimproved water.

The Kendall's W shows a statistic value of 0.09 (9.0\%), suggesting a low level of agreement by the respondents on the ranking. The chi-square value was 261.03 with a degree of freedom (df) value of 8 because 9 constraints were ranked by the respondents. Finally, the significance level showed was 0.00 .

\section{CONCLUSION}

For the multinomial regression, comparing boreholes with wells (base) variables that were statistically significant included, years of education, the income level of households, perception on the price of improved water, perception on open hours and access time. Tap in comparison with well (base) household income, distance, perception on the price of improved water, open hours and access time were found to be significant. Finally, for river against well (base) education of household head, perception on location, price, open hours, access time and reliability were found to be factors that determine the use of river relative to wells.

Results from the Logit regression shows that educational attainment of household head, income level of households, sex of household head, number of children in household, distance to improved water, and certain perception responses (opening hours of improved water system, hardness of improved water, reliability) had significant effect on improved water use. The number of children in a household, distance to improved water, perception on opening hours and reliability were the factors that had a negative influence on improved water use. Irregular supply of improved water was the key constraint limiting access to improved water followed by inadequate improved water sources while long distance was ranked as the last constraint.

The following policy recommendations are made to help promote access and use of improved water in the Bunkpurugu-Nakpanduri District, Ghana and in the long run achieve good health for sustainable development:

- Income diversification campaign should be carried out by government bodies and other related institutions to encourage households to raise incomes which will as well raise their purchasing power for improved water. This is because average households' income (GHC 6,178 per annum) realized from the study classified households in the low income state, meanwhile income and use of a particular water source (improved or not) was found to be significant;

- Households should be encouraged through education to use improved water sources so as to promote health and improve the living standard of its members. They should, therefore, be educated on benefits that come with the use of improved water sources. Proper education will enhance household use of improved water regardless existing constraints;

- There should also be an equitable payment scheme for water in Ghana. This will help overcome a major challenge (income) of the low-income households not being able to access improved water because of their class. This payment scheme/ policy will ensure access to improved water by all. 


\section{FUNDING SOURCES}

This work did not receive any funding from an external source. All expenses were solely done by the authors.

\section{REFERENCES}

1. Abubakar, I. R. (2017). Access to sanitation facilities among Nigerian households: determinants and sustainability implications, Sustainability, vol. 9, no. 4, p. 547.

2. Adams, E. A., Boateng, G. O., and Amoyaw, J. A. (2016). Socioeconomic and demographic predictors of potable water and sanitation access in Ghana,Social Indicators Research, vol. 126, no. 2, pp. 673-687.

3. Adebisi, G. L., Oyebode, L. A., \& Olubode, T (2017). Constraints of rural households to access improved drinking water in oyo state, nigeria.

4. Boateng, D., Tia-Adjei, M., and Adams, E. A. (2013). Determinants of household water quality in the Tamale Metropolis, Ghana, Journal of Environment and Earth Science, Vol. 3, No. 7, pp. 70-77.

5. Boone, C., Glick, P., \& Sahn, D. E. (2011). Household water supply choice and time allocated to water collection: Evidence from Madagascar. Journal of Development Studies, 47(12), 1826-1850.

6. Bunkpurugu District Assembly (2018). Composite Budget for 2018-2021. Ghana.

7. Cairncross S, Hunt C, Boisson S, Bostoen K, Curtis V, Fung ICH, et al. (2010). Water, sanitation and hygiene for the prevention of diarrhea. Int J Epidemiol.; 39 Suppl 1:i193205.

8. Dil, B. R., Behera, B.and Ali, A. (2015). Household access to water and choice of treatment methods: empirical evidence from Bhutan,Water Resources and Rural Development, vol. 5, pp. 1-16.

9. Engel, S., Iskandarani, M., \& del Pilar Useche, M. (2005). Improved water supply in the Ghanaian Volta Basin: Who uses it and who participates in community decision-making?. Intl Food Policy Res Inst.

10. Ghana Statistical Service (2014). The District Analytical Report for the BunkpuruguYunyo District. Accra Ghana.

11. Gujarati, D., \& Porter, D. (2003). Multicollinearity: What happens if the regressors are correlated. Basic Econometrics, 363.

12. Ladele, A. A., \& Tackie-Ofosu, V. (2013). Gender analysis of commitment and participation in rural water supply project in Suhum Kraboa Coaltar district of the Eastern region of Ghana. Journal of Sustainable Development in Africa, 15(4), 86-98.

13. Montgomery, M. A., Bartram, J., \& Elimelech, M. (2009). Increasing functional sustainability of water and sanitation supplies in rural sub-Saharan Africa. Environmental Engineering Science, 26(5), 1017-1023.

14. Mulenga, J. N., Bwalya, B. B., and Kaliba-Chishimba, K. (2017). Determinants and inequalities in access to improved water sources and sanitation among the Zambian households, International Journal of Development and Sustainability, vol. 6, no. 8, pp. 746-762.

15. Omole, D. O. \& Okunowo, O. S. (2015). People Perception of Domestic Water Supply Situation in Ogun State, Nigeria. Research Journal of Applied Sciences, Engineering, and Technology 12(1): 94-99, 2016.

16. Onda, K., LoBuglio, J., Bartram, J. (2012). Global Access to Safe Water: Accounting for Water Quality and the Resulting Impact on MDG Progress. Int $\mathrm{J}$ Environ Res Public Health; 9:880-94.

17. Rauf, S., Bakhsh, K., Hassan, S., Nadeem, A. M., \& Kamran, M. A. (2015). Determinants of a household's choice of drinking water source in Punjab, Pakistan. Polish Journal of Environmental Studies, 24(6), 2751-2754. 
18. Rojas, L. F. R., Megerle, A., \& Araral, E. (2013). Perception of water quality and health risks in the rural area of Medellín. American Journal of Rural Development, 1(5), 106115.

19. UNICEF/WHO (2008). Progress on Drinking water sanitation: Special Focus on Sanitation.

20. UNICEF/WHO (2012). Progress on Drinking Water and Sanitation: 2012 Update. UNICEF and World Health Organization, New York, pp: 59, ISBN: 978-92-806-4632-0.

21. UNICEF/WHO. (2015). Progress on sanitation and drinking water - 2015 update and MDG assessment.

22. Wright, J. A., Yang, H., Rivett, U., \& Gundry, S. W. (2012). Public perception of drinking water safety in South Africa 2002-2009: a repeated cross-sectional study. BMC Public Health, 12(1), 556. 